\title{
Apaf-1-deficient fog mouse cell apoptosis involves hypo- polarization of the mitochondrial inner membrane, ATP depletion and citrate accumulation
}

\author{
Iyoko Katoh ${ }^{1}$, Shingo Sato $^{2}$, Nahoko Fukunishi ${ }^{3}$, Hiroki Yoshida ${ }^{4}$, Takasuke Imai ${ }^{5}$, Shun-ichi Kurata ${ }^{3}$ \\ ${ }^{1}$ Department of Microbiology, Interdisciplinary Graduate School of Medicine and Engineering, University of Yamanashi, Yamanashi \\ 409-3898, Japan; ' Department of Immunoregulation, Tokyo Medical and Dental University, 1-5-45 Yushima, Bunkyo-ku 113-8510, \\ Japan; ${ }^{3}$ Redox Response Cell Biology, Medical Research Institute, Tokyo Medical and Dental University, 1-5-45 Yushima, Bunkyo-ku \\ 113-8510, Japan; ${ }^{4}$ Department of Biomolecular Sciences, Faculty of Medicine, Saga University, Saga 849-8581, Japan; ${ }^{5}$ Department \\ of Critical Care Medicine, Tokyo Medical and Dental University, 1-5-45 Yushima, Bunkyo-ku 113-8510, Japan
}

To explore how the intrinsic apoptosis pathway is controlled in the spontaneous fog (forebrain overgrowth) mutant mice with an Apaf1 splicing deficiency, we examined spleen and bone marrow cells from ApafI $^{+/+}(+/+)$and ApafI $^{\text {foglfog }}$ ( $f \circ g / f \circ g$ ) mice for initiator caspase-9 activation by cellular stresses. When the mitochondrial inner membrane potential $(\Delta \psi \mathrm{m})$ was disrupted by staurosporine, $+/+$ cells but not $f \circ g / f \circ g$ cells activated caspase- 9 to cause apoptosis, indicating the lack of apoptosome (apoptosis protease activating factor 1 (Apaf-1)/cytochrome $c /(d) A T P / p r o c a s p a s e-9)$ function in fog/fog cells. However, when a marginal $(20 \%)$ decrease in $\Delta \psi \mathrm{m}$ was caused by hydrogen peroxide $(0.1 \mathrm{mM})$, peroxynitrite donor 3-morpholinosydnonimine $(0.1 \mathrm{mM})$ and $\mathrm{UV}-\mathrm{C}$ irradiation $\left(20 \mathrm{~J} / \mathrm{m}^{2}\right)$, both $+/+$ and $f \circ g / f \circ g$ cells triggered procaspase-9 auto-processing and its downstream cascade activation. Supporting our previous results, procaspase-9 pre-existing in the mitochondria induced its auto-processing before the cytosolic caspase activation regardless of the genotypes. Cellular ATP concentration significantly decreased under the hypoactive $\Delta \psi \mathrm{m}$ condition. Furthermore, we detected accumulation of citrate, a kosmotrope known to facilitate procaspase-9 dimerization, probably due to a feedback control of the Krebs cycle by the electron transfer system. Thus, mitochondrial in situ caspase-9 activation may be caused by the major metabolic reactions in response to physiological stresses, which may represent a mode of Apaf-1-independent apoptosis hypothesized from recent genetic studies.

Keywords: apoptosis, Apaf-1, caspase-9, mitochondria, citrate, ATP

Cell Research (2008) 18:1210-1219. doi: 10.1038/cr.2008.87; published online 29 July 2008

\section{Introduction}

Activation of initiator caspase-9 determines the onset of the mitochondrion-linked intrinsic pathway of apoptosis in response to diverse cellular stresses. In the original model, formation of 'apoptosome' comprising apoptosis protease activating factor 1 (Apaf-1), cytochrome $c$ and procas-

Correspondence: Shun-ichi Kurata

Tel/Fax: +81-3-5803-4695

E-mail: kushbgen@mri.tmd.ac.jp

Abbreviations: MMP (mitochondrial membrane permeabilization); $\Delta \psi \mathrm{m}$ (mitochondrial inner membrane potential); Apaf-1 (apoptosis protease activating factor 1); MEF (mouse embryonic fibroblasts); STS (staurosporine); Sin-1 (3-morpholinosydnonimine)

Received 8 April 2008; revised 15 June 2008; accepted 20 June 2008; published online 29 July 2008 pase-9 is assumed to be the only mechanism to convert procaspase- 9 to the active form caspase- 9 in the cytosol [1-4]. The association between Apaf-1 and procaspase-9 is mediated by the caspase-recruitment domain (CARD) of each protein, where cytochrome $c$ and ATP/dATP are required as cofactors [2, 5-7]. According to this model, translocation of cytochrome $c$, the ion carrier associated with the complexes III and IV of the mitochondrial electron transfer system, to the cytosol is an essential event for the apoptosis cascade activation.

The mechanism of cytochrome $c$ translocation has been explained by a phenomenon termed mitochondrial membrane permeabilization (MMP) [8]. Proapoptotic Bcl-2 family proteins, the effector molecules of various death signal pathways, induce a full permeability transition or a short-lived permeability pore opening of the outer 
membrane, depending on the assay systems [8-10]. The former is associated with failure of the inner membrane potential $(\Delta \psi \mathrm{m})$ and matrix swelling, whereas the latter is not. Substantial remodeling of the mitochondrial ultrastructure was also reported [11]. Reactive oxygen species (ROS) excessively produced by the respiratory chain can also cause the progressive mitochondrial damage leading to apoptosis [12]. All of the proposed cytochrome $c$-releasing mechanisms, however, remain hypothetical, and fail to provide a physiological basis underlying naturally occurring apoptosis.

Apaf1-null mice frequently exhibit morphological defects in the forebrain [13, 14]. However, a fraction of Apafl $^{-}$ ${ }^{-}$animals survive, suggesting that Apaf-1 plays its role in limited physiological contexts [14]. Either Apaf-1-deficient or caspase-9-deficient thymocytes could induce varied apoptotic responses to irradiation and dexamethasone [15]. Apaf-1-deficient primary myoblasts could activate caspase9, which suggested that coupling of caspase-9 with Apaf-1 is cell type-specific [16]. A similar observation was made with Drosophila melanogaster lacking ARK, the fly homologue of Apaf-1 [17]. Apoptosome-independent, but Apaf1-dependent, caspase activation was detected in thymocytes having a mutant cytochrome $c$ [18]. Apoptosis-inducing mechanisms distinct from the apoptosome model deserve more extensive investigation by various approaches.

In fact, procaspase-9 is able to homo-dimerize to gain its enzyme activity in the absence of Apaf- 1 as evidenced by bacterial expression systems, in vitro translation and biochemical analyses [7, 19-22]. More importantly, procaspase-9 is dimerized by higher concentrations of kosmotropes, salts able to stabilize proteins, such as $1 \mathrm{M}$ citrate $[21,22]$. Citric acid is the first product in the Krebs (citric acid) cycle whose reactions are controlled by the electron transfer system maintaining $\Delta \psi \mathrm{m}$ for ATP synthesis. Furthermore, a population of procaspase- $9 /$ caspase- 9 and other caspases pre-exist in the intermembrane space of mitochondria and participate in apoptosis [23-25]. As we showed, a level of oxidative stress that causes a hypoactive $\Delta \psi \mathrm{m}$ condition leads to intra-mitochondrial caspase- 9 activation, showing a sign of dimerization [26] and cytosolic translocation which can be prevented by Bcl-2 [25, 26].

Apaff ${ }^{\text {fog/fog }}(f \circ g / f o g)$ mice bear an Apafl deficiency due to mis-splicing between exons 3 and 4 of the transcript, and exhibit brain phenotypes similar to Apaf1 ${ }^{-/}$mice, but live to adulthood [27]. The nucleotide sequences in intron 3 (Ensemble Gene ID: ENSMUSG00000019979) indicate premature termination of the mRNA translation to produce a CARD domain-only protein corresponding to a dominant-negative type suppressor against Apaf-1 [28]. To gain deeper insight into physiologically induced apoptosis, we ex vivo examined fog mouse cells for caspase-9 induction, focusing on changes in $\Delta \psi \mathrm{m}$. In addition to the Apaf-1dependent ultimate pathway to apoptosis, cells may have a branched, flexible pathway that can deal with stresses inside the mitochondria.

\section{Results}

Detection of caspase-9 activation in fog/fog and $+/+$ mice

Heterozygous Apaf1 ${ }^{f o g /+}$ pairs were mated to obtain Apafl $^{+++}(+/+)$and Apafl fog/fog (fog/fog) progeny. The genotypes were assessed by RT-PCR with the intron 3spanning primer pairs, in which the $A p a f 1^{+}$and $A p a f 1^{f o g}$ alleles appeared at the expected Mendelian ratio [27]. The fog/fog newborns frequently displayed exencephaly and cranioschesis corresponding to the Apafl knockout (KO) mice (Figure 1A and 1B).

Spleen cells from 9 newborn mice of the L1 litter, 14 days old, were ex vivo examined for initiator caspase- 9 activation by incubation with $0.1 \mathrm{mM} \mathrm{H}_{2} \mathrm{O}_{2}$ as described [26]. Conversion of the 49 kilodalton ( $\mathrm{kDa}$ ) procaspase- 9 (of mouse) to the auto-processed form, $37 \mathrm{kDa}$ caspase-9, was observed in all cultures $5 \mathrm{~h}$ after exposure to $\mathrm{H}_{2} \mathrm{O}_{2}$, but not in the control culture without $\mathrm{H}_{2} \mathrm{O}_{2}$ (Figure 1C). The 24 $\mathrm{kDa}$ segment of anti-poly(ADP-ribose) polymerase (PARP) also appeared in $\mathrm{H}_{2} \mathrm{O}_{2}$-induced samples, indicating the downstream caspase- 3 activation. A control culture without $\mathrm{H}_{2} \mathrm{O}_{2}$ failed to show the PARP cleavage (Figure 1C, sample $2,-)$. A faint band of $39 \mathrm{kDa}$ caspase- 9 was also detectable, reflecting procaspase- 9 processing by caspase-3, which increased further as the apoptosis reactions progressed [26]. Since auto-processing of procaspase- 9 occurs by its activation through homo-dimerization, the $37-\mathrm{kDa}$ form was thought to signify induction of the caspase- 9 pathway $[7,19,20,22]$. This initial experiment suggested that $+/+$ and $f \circ g / f o g$ cells were equally capable of capase- 9 activation in response to the oxidative stress.

\section{Apoptosis induction in $+/+$ and fog/fog spleen cells by} various stimulants

We examined splenocytes from 6-week-old mice for apoptosis induction by incubation with oxidative stress inducer $\mathrm{H}_{2} \mathrm{O}_{2}(0.1 \mathrm{mM}), 3$-morpholinosydnonimine (Sin1) $(0.1 \mathrm{mM})$, known to cause nitrosative stress molecule peroxynitrite $\left(\mathrm{ONOO}^{-}\right)$, and staurosporine (STS) $(10 \mu \mathrm{M})$, a generally used apoptosis inducer. UV-C irradiation (20 $\mathrm{J} / \mathrm{m}^{2}$ ) was also carried out. Processing of procaspase-9 to caspase-9, its enzyme activity and nuclear morphological changes were monitored.

In the $+/+$ cultures stimulated with STS, approximately $30 \%$ of the cells showed nuclear condensation and fragmentation at $5 \mathrm{~h}$ (Figure 2A and 2B). Western blotting 


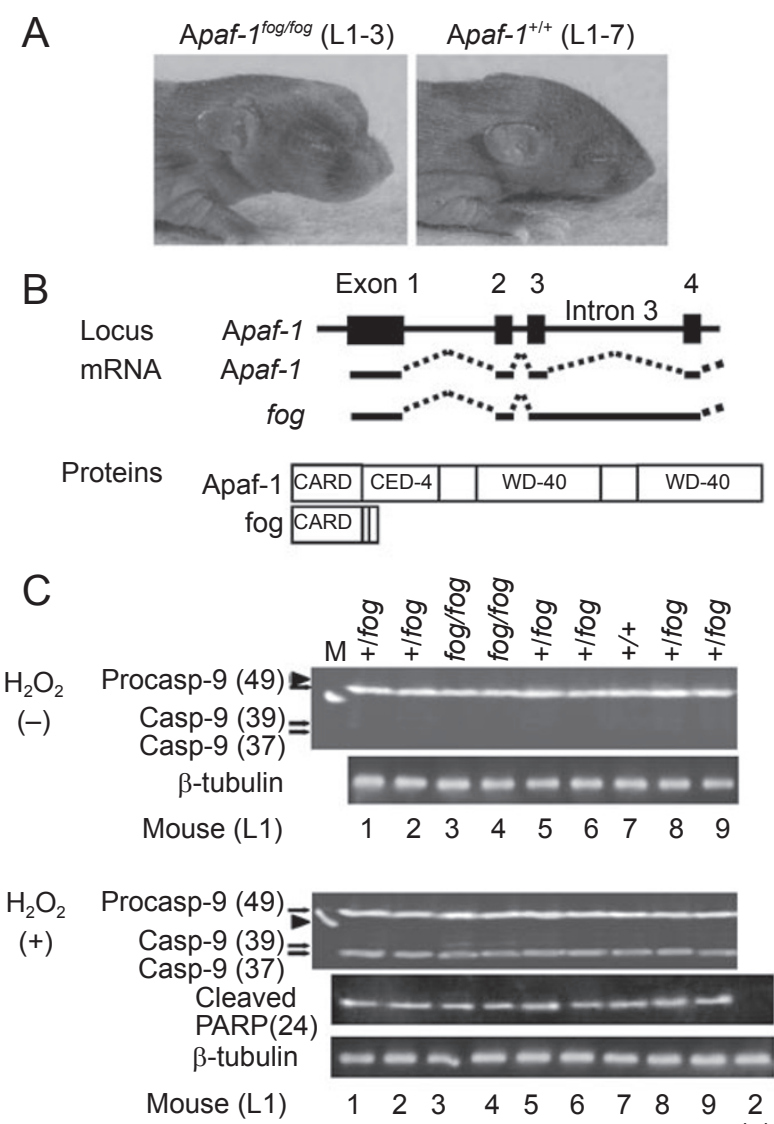

$(-)$

Figure 1 Detection of procaspase-9 processing in fog/fog mutant mice. (A) Heterozygous (+/fog) mice were mated to screen their offspring for $+/+$ and fog/fog homozygous animals. Anterior portions of the L1-3 (fog/fog) and L1-7 (+/+) littermates were photographed at postnatal day 7 . The morphological defects in the brain represent the fog mutation [27]. (B) Structures of the fog mRNA and its translation product. The exon-intron structure of the $5^{\prime}$ terminus of the Apaf1 gene is aligned with Apaf1 and fog mRNAs. Dotted line indicates splicing. The fog mRNA retains the third intron by mis-splicing [27] to encode the entire CARD domain followed by 25 unrelated amino acid sequences. The Apaf-1 domain structure is also aligned. (C) Procaspase- 9 autoprocessing in spleen cells from the $\mathrm{L} 1$ littermates. Cells were incubated either with $(+)$ or without (-) $0.1 \mathrm{mM}$ of $\mathrm{H}_{2} \mathrm{O}_{2}$ for $5 \mathrm{~h}$, and the proteins analyzed by Western blotting. Molecular masses of the proteins are indicated in kilodaltons (kDa). Positions of $49 \mathrm{kDa}$ procaspase-9 (Procasp9) as well as 37 and 39 kDa caspase-9 (Casp-9) are indicated. Cleaved PARP (24 kDa) is also shown. $\beta$-Tubulin was analyzed as a control protein. The $45 \mathrm{kDa}$ biotinylated standard protein in lane $\mathrm{M}$ is marked with an arrowhead.

detected caspase- 9 at 37 and $39 \mathrm{kDa}$ (Figure 2C). Cleavage of PARP was also evident. A substantial increase in the AcLEHD-pNA cleaving (LEHDase) activity was observed, implying activation of caspase-9 and caspase-3 (Figure 2D) [29]. LEHD-CHO, a peptide inhibitor against the caspase-9 pathway, protected $+/+$ cells from STS-induced apoptosis (Figure 2B and 2D). In contrast, fog/fog cells neither activated the death protease cascade nor exhibited an apoptotic morphology at $5 \mathrm{~h}$. The Apaf-1-dependent capase-9 activation mechanism was unquestionably vital in apoptosis induced by STS.

After exposure to $\mathrm{H}_{2} \mathrm{O}_{2}$, Sin-1 and UV-C, however, both $+/+$ and fog/fog cells were equally capable of initiating apoptosis. Nuclear fragmentation, auto-processing of procaspase-9, LEHDase activation and PARP cleavage were obvious at $5 \mathrm{~h}$ (Figure 2A-2C). LEHD-CHO inhibited the $+/+$ and $f \circ g / f o g$ cell death triggered by these stimuli. Furthermore, thioredoxin (TRX), a thiol-disulfide oxidoreductase, also blocked cell death induced by these stimuli (Figure 2B and 2D), suggesting involvement of a redox regulatory system. These results implied that cells have an Apaf-1-independent caspase-9 activation mechanism inducible by varied stresses.

\section{Oxidative stress-induced apoptosis in Apaf1-KO mouse fibroblasts}

We next tested mouse embryonic fibroblasts (MEF) from Apaf1-wildtype (WT) and-KO animals for cell death induction by $\mathrm{H}_{2} \mathrm{O}_{2}$. After $5 \mathrm{~h}$ incubation with $0.2 \mathrm{mM} \mathrm{H}_{2} \mathrm{O}_{2}$, cells in both cultures manifested morphological features of apoptosis at the same efficiency (approximately 25\%) (Figure $3 \mathrm{~A}$ and $3 \mathrm{~B}$ ). The dying cell population had increased to $70 \%$ at $10 \mathrm{~h}$. Auto-processed caspase- 9 ( $37 \mathrm{kDa})$ was detected as a major product by Western blotting at 5 and $10 \mathrm{~h}$. A decrease in PARP (116 kDa) and generation of the long PARP fragment ( $83 \mathrm{kDa}$ ) was also evident (Figure 3C). Not only LEHD-CHO but also membrane-permeable TRX inhibited the cell death efficiently (Figure 3B). Thus, WT and KO MEF seemed to activate a common mechanism for caspase activation in response to the less stringent oxidative stress. Presence of an Apaf-1-independent caspase-9 activation mechanism was strongly suggested.

We were able to detect a trace of apoptotic morphology in MEF after incubation with $0.1 \mathrm{mM} \mathrm{H}_{2} \mathrm{O}_{2}$ for $24 \mathrm{~h}$. If exposed to $>0.4 \mathrm{mM}$ of $\mathrm{H}_{2} \mathrm{O}_{2}$, MEF detached from the basement within $1 \mathrm{~h}$, long before the induction of cell death.

\section{Apaf-1 dependency correlated with the range of $\Delta \psi m$ damage}

Using expanded cultures of bone marrow mast cells (BMMC), we assessed plasma membrane rearrangement and loss of $\Delta \psi \mathrm{m}$ by flow cytometry using Annexin $\mathrm{V}$ and 3,3'-dihexyloxacarbocyanine $\left(\operatorname{DiOC}_{6}(3)\right)$ as the probes, respectively $[26,30]$. As early as $1 \mathrm{~h}$ after exposure to STS, a substantial $(69 \pm 5 \%)$ decrease in $\Delta \psi \mathrm{m}$ was observed in both $+/+$ and $f \circ g / f o g$ cells, without a significant increase in the Annexin V-positive cell population (Figure 4A and 
A

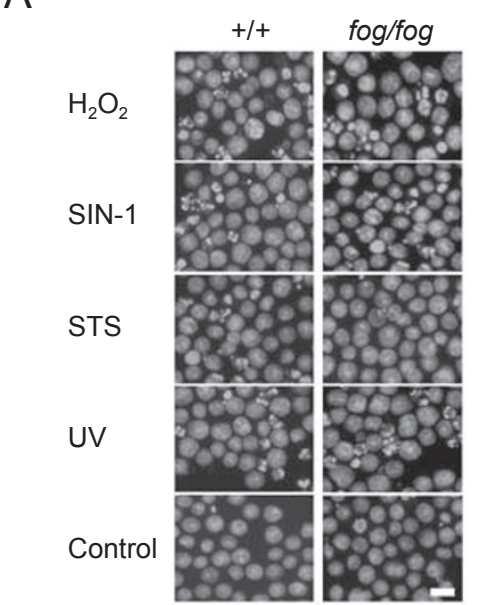

B



C

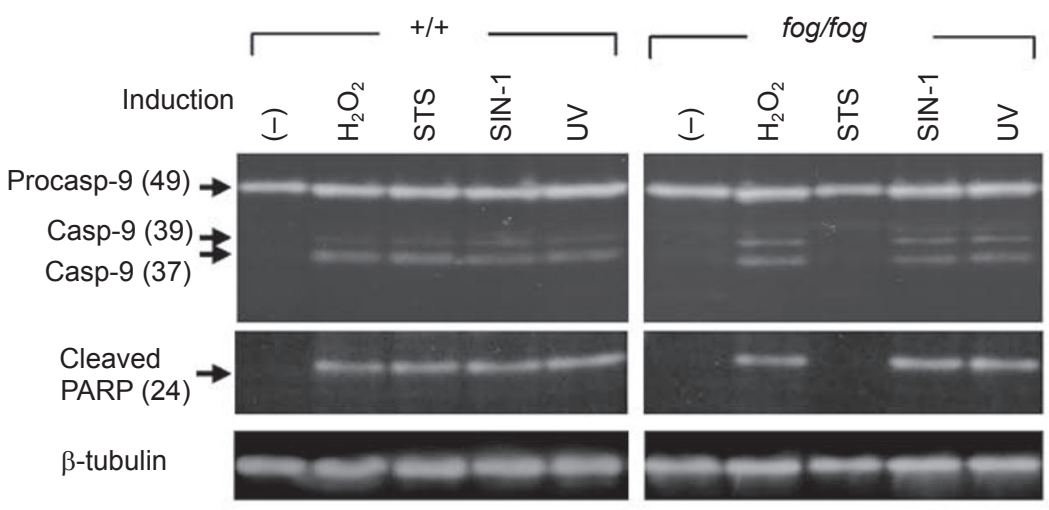

D

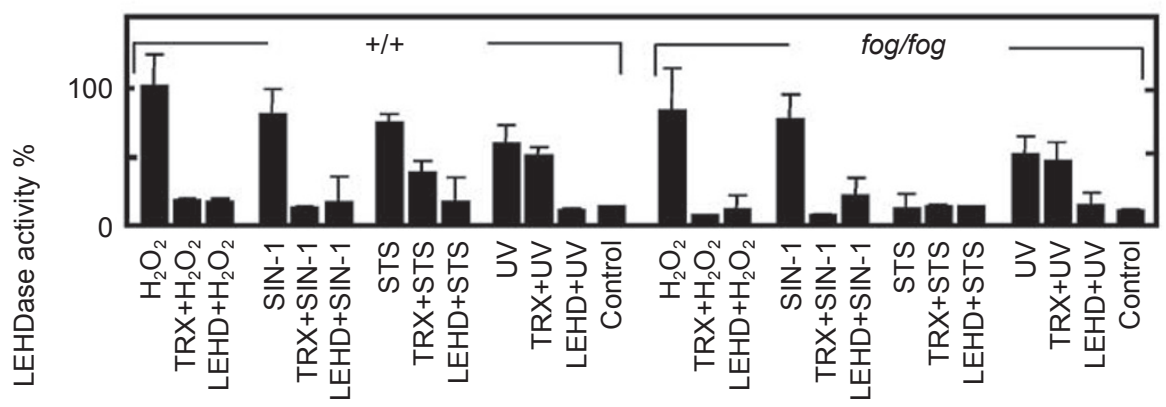

Figure 2 Induction of the caspase- 9 cascade in +/+ and fog/fog cells. Spleen cells from $+/+$ and fog/fog mice were exposed to STS and physiological stimulants. (A) Detection of nuclear condensation and fragmentation by Hoechst staining $5 \mathrm{~h}$ after exposure to $\mathrm{H}_{2} \mathrm{O}_{2}(0.1 \mathrm{mM})$, SIN-1 (Sin-1) $(0.1 \mathrm{mM})$, STS $(10 \mu \mathrm{M})$ and UV $\left(20 \mathrm{~J} / \mathrm{m}^{2}\right)$. The scale bar indicates $10 \mu \mathrm{m}$. (B) Apototic cell population (\%) determined by fluorescence microscopic pictures as shown in (A). Apoptotic and non-apoptotic cells were counted for 3 views (200 cells in each view). Cultures pretreated with TRX or LEHD-CHO (denoted by LEHD) for $1 \mathrm{~h}$ prior to exposure to the stimulants were also analyzed. (C) Caspase- 9 activation in fog/fog cells by various stresses. Normal $(+/+)$ and fog/fog spleen cells stimulated with $\mathrm{H}_{2} \mathrm{O}_{2}$, SIN-1, STS and UV-C were analyzed for processing of procaspase- 9 and PARP by Western blotting. Control untreated cell lysates are in the lanes marked (-). (D) Induction of LEHDase activity. A colorimetric assay was performed $5 \mathrm{~h}$ after stimulation. Relative activities are presented in per cent in comparison with $\mathrm{H}_{2} \mathrm{O}_{2}$-induced cells $(100 \%)$. In (B) and (D), each point represents the mean value with \pm SD (error bar) in triplicate reactions. Similar results were obtained in two separate experiments.

4B). At $5 \mathrm{~h}$ of the drug application, an approximately $90 \%$ population of the $+/+$ cultures had turned Annexin V-posi- tive without a further decrease in $\Delta \psi \mathrm{m}$. In contrast, $\sim 85 \%$ of the fog/fog cells remained Annexin V-negative at $5 \mathrm{~h}$, 

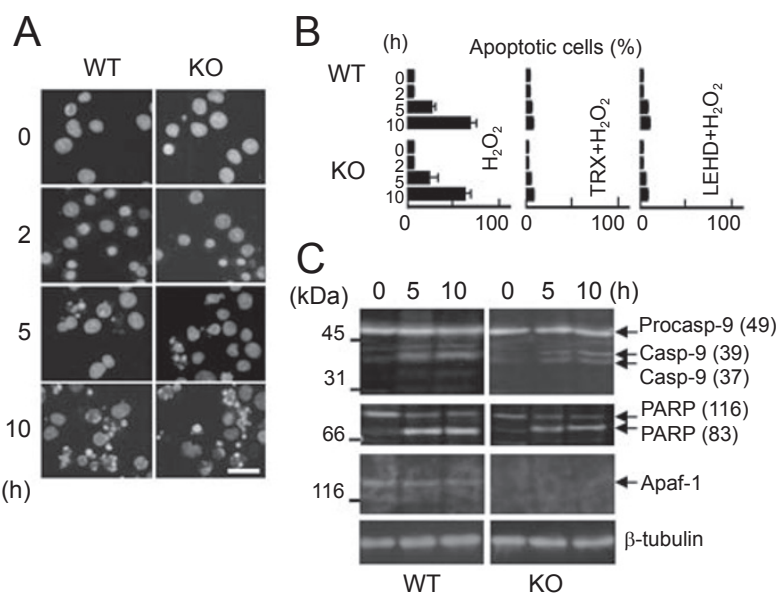

Figure 3 Apoptosis of Apaf1-KO MEF in response to oxidative stress. (A) MEF from WT and Apaf1-KO mice were incubated with $\mathrm{H}_{2} \mathrm{O}_{2}$ and analyzed for apoptotic changes. Nuclear Hoechst staining at indicated times in hours (h). The scale bar indicates $50 \mu \mathrm{m}$. (B) Apoptotic cell populations (\%) during the time course. Each point indicates the mean SD of triplicate reactions. Shown here is one of the two experiments in which results were comparable. (C) Procaspase-9 processing detected by Western blotting. Positions of 49-kDa procaspase-9 (Procasp-9) and the 37- and 39-kDa fragments of caspase-9 (Casp-9) are indicated. Full-length PARP (116 kDa) and the longer cleavage product (83 kDa) were also detected. By probing with an anti-Apaf-1 antibody, WT and $\mathrm{KO}$ cell samples were verified.

with the $\Delta \psi m$ level equal to that of $+/+$ cells. Thus, $f \circ g / f o g$ cells were resistant to STS-induced apoptosis, despite the sudden fall of $\Delta \psi \mathrm{m}$.

Cells stimulated by $\mathrm{H}_{2} \mathrm{O}_{2}$, Sin-1 and UV-C displayed only a minor decrease $(17 \pm 2 \%, 19 \pm 3 \%$ and $24 \pm 1 \%$, respectively) in $\Delta \psi \mathrm{m}$ at $1 \mathrm{~h}$, and were negative for Annexin $\mathrm{V}$ staining. Interestingly, nearly the entire population ( $\geq 93 \%)$ of the $+/+$ and $f o g / f \circ g$ cultures became Annexin V-positive after $5 \mathrm{~h}$, suggesting that Apaf-1-independent apoptosis was induced after a duration of hypo- $\Delta \psi \mathrm{m}$. The level of $\Delta \psi \mathrm{m}$ did not decline further for at least $5 \mathrm{~h}$.

At $5 \mathrm{~h}$ of incubation with STS, both $+/+$ and $f \circ g / f o g$ cells contained a large amount of cytochrome $c$ in the cytosol, showing concomitant loss of the protein from the mitochondria (Figure 5A). In contrast, the localization of cytochrome $c$ was not altered in $\mathrm{H}_{2} \mathrm{O}_{2}$-induced apoptosis of $+/+$ and fog/fog cells as analyzed by western blotting. The mitochondrial fractions obtained in this experiment were abundant in Cox IV, an inner membrane protein, while the cytosol fractions were free of the protein. Conversely, heat shock protein 90 (HSP90), a molecular chaperone protein, was localized in the cytosol, and only a minimum amount was detectable in the mitochondrial fractions. Together with the results in Figure 2, these data (Figures 4 and 5A) suggested that STS caused a large loss of $\Delta \psi \mathrm{m}$, thereby mobilizing a large amount of cytochrome $c$ to trigger the canonical Apaf-1-dependent caspase-9 activation cascade. The other inducers caused a hypo- $\Delta \psi \mathrm{m}$ condition, where cytochrome $c$ was retained in the mitochondria, leading to caspase-9 activation through an Apaf-1-independent mechanism.

\section{ATP depletion and citrate accumulation caused by hypo-} $\Delta \psi m$

To examine biochemical outcomes of the two different types of $\Delta \psi m$ impairment, we performed semi-quantification of the whole cell ATP amount using a luciferase-based

A

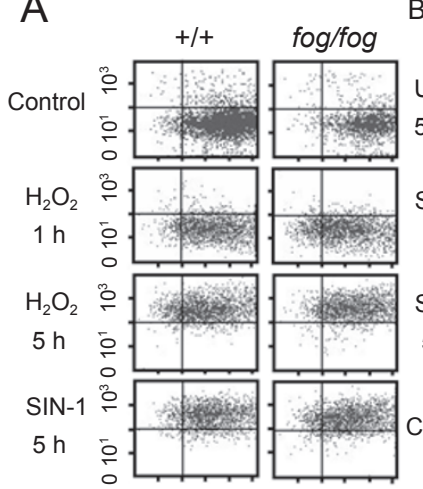

BMMC

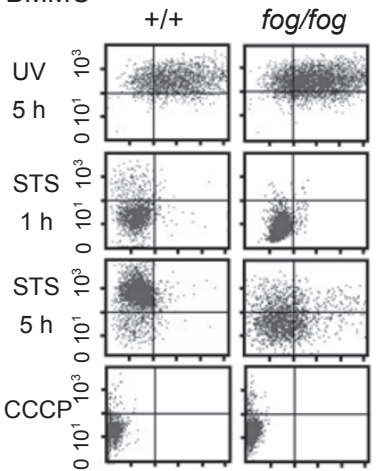

B

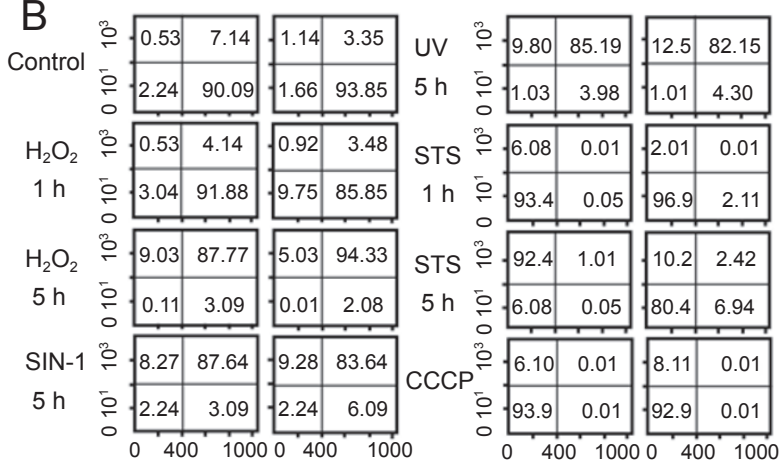

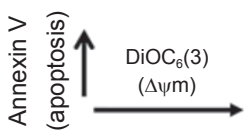

Figure 4 Apaf-1-dependent apoptosis induction is characterized by hypo- $\Delta \psi$ m caused by varied stimuli. (A) Flow cytometric analysis of BMMC $(+/+$, fog/fog $)$ for $\Delta \psi m$ and apoptosis. At the indicated time points $\left(\mathrm{h}\right.$ ) after stimulation with $\mathrm{H}_{2} \mathrm{O}_{2}$, SIN-1, STS and UV-C, cells were stained with $\mathrm{DiOC}_{6}(3)$ and Annexin $\mathrm{V}$ for detection of $\Delta \psi \mathrm{m}$ and plasma membrane rearrangement, respectively. Complete depolarization of $\Delta \psi \mathrm{m}$ was demonstrated by 5 -min incubation with carbonyl cyanide 3-chlorophenylhydrazone (CCCP) at room temperature. Similar results were obtained by two independent experiments. One complete set is presented. (B) Numerical presentation of the two-dimensional dot plots shown in (A). 
A
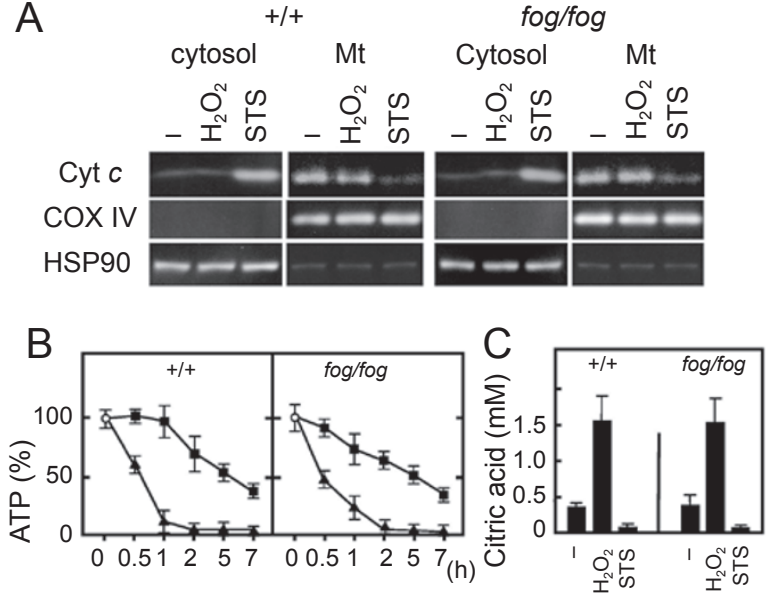

Figure 5 Comparison of biochemical alterations in BMMC by $\mathrm{H}_{2} \mathrm{O}_{2}$ and STS. (A) Analysis of cytosol fractions for cytochrome $c$ (Cyto $c$ ) content. Mitochondrial and cytosolic fractions were obtained from BMMC incubated for $5 \mathrm{~h}$ with $\mathrm{H}_{2} \mathrm{O}_{2}$ and STS as well as cells without stimulation (-). Both $+/+$ and fog/fog genotypes were tested. Western blots for cytochrome $c$, mitochondrial marker protein COX IV and cytosol protein HSP90 are shown. (B) Semi-quantification of cellular ATP. ATP amount at each time point $(0.5,1,2,5,7-h)$ is shown in relation to the amount in the control cell lysate (100\%). Triangles and squares indicate cells exposed to $\mathrm{H}_{2} \mathrm{O}_{2}$ and STS, respectively. (C) Determination of citric acid amounts in cell extracts prepared at $3.5 \mathrm{~h}$ of incubation with $\mathrm{H}_{2} \mathrm{O}_{2}$ and STS. Citrate concentration is presented in $\mathrm{mM}$. Experiments in $\mathrm{B}$ and $\mathrm{C}$ were performed three times with different pairs of $+/+$ and fog/fog mice. The mean values and standard deviations (error bars) are indicated.

assay (Figure 5B). In STS-stimulated cells of $+/+$ and fog/fog, ATP amount was not significantly altered by the sudden fall of $\Delta \psi \mathrm{m}$ (at $1 \mathrm{~h}$ ). Instead, we observed a gradual decline of the ATP level to approximately $60 \%$ at $5 \mathrm{~h}$, consistent with a recent study [31]. Given that $\Delta \psi \mathrm{m}$ disruption means shutdown of the mitochondrial ATP-producing function of the respiratory chain on the inner membrane, this result indicated that most of the cellular ATP-consuming reactions also stopped. On the contrary, $\mathrm{H}_{2} \mathrm{O}_{2}(0.1 \mathrm{mM})$ caused a significant decrease in ATP, reaching $5 \%$ of the control level $2 \mathrm{~h}$ after incubation, or $3 \mathrm{~h}$ before the onset of apoptosis. This ATP depletion may have resulted from the imbalance between vital ATP consumption in the preapoptotic phase and impaired ATP production due to the $\Delta \psi \mathrm{m}$ hypo-polarization.

We next carried out citric acid quantification by an enzyme-based reaction (Figure 5C). The measured citrate in the control $+/+$ cell extract was $0.41 \pm 0.06 \mathrm{mM}$, within the range of the normal physiological concentration, 0.1$1 \mathrm{mM}$ [32] At $3.5 \mathrm{~h}$ of incubation with STS, a significant decrease in citric acid (to $20 \%$ of the normal level, 0.078
$\mathrm{mM}$ ) was observed, suggesting cleavage of citrate by citrate lyase, a cytosolic enzyme, after mitochondrial swelling. Conversely, $\mathrm{H}_{2} \mathrm{O}_{2}$ caused a 3.7-fold increase in citrate to $1.51 \pm 0.39 \mathrm{mM}$, implying citrate accumulation in the mitochondria due to the feedback suppression of the Krebs cycle by the hypo-polarized electron transfer system [33]. fog/fog cells displayed comparable decrease or increase in citrate $3.5 \mathrm{~h}$ after incubation with STS or $\mathrm{H}_{2} \mathrm{O}_{2}$.

\section{Activation of caspase-9 associated with mitochondria}

We performed cell fractionations to investigate the site of initial activation of caspase-9 in stress-induced apoptosis. Mitochondrial and cytosolic fractions were obtained in the course of $\mathrm{H}_{2} \mathrm{O}_{2}$-induced BMMC apoptosis. The purity of these fractions was confirmed by the contents of COX IV and HSP90 as described above. Western blotting showed generation of auto-processed caspase- $9(37 \mathrm{kDa})$ in the mitochondria $2 \mathrm{~h}$ after the input of $\mathrm{H}_{2} \mathrm{O}_{2}$ (Figure 6B). In the cytosol fractions, an increase in the mature protein band became obvious at $5 \mathrm{~h}$, leading to a further enhancement at $7 \mathrm{~h}$. LEHDase activity was first detectable at $2 \mathrm{~h}$ in the mitochondrial fraction from either $+/+$ or fog/fog cells (Figure 6A). The enzyme activity in the mitochondria slightly

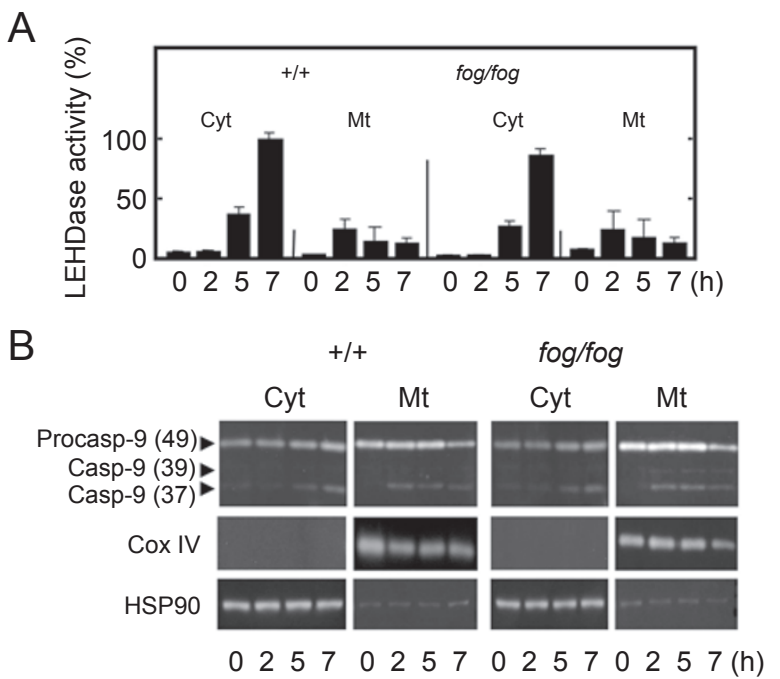

Figure 6 Activation of caspase- 9 associated with mitochondria. (A) Levels of LEHDase activity in the mitochondrial (Mt) and cytosol (Cyt) fractions. Cells were fractionated at indicated time intervals after stimulation with $\mathrm{H}_{2} \mathrm{O}_{2}$. Enzyme activity at each time point (h) is indicated in relation to the maximum activity in the cytosol of the $\mathrm{H}_{2} \mathrm{O}_{2}$-induced $+/+$ cells at $7 \mathrm{~h}(100 \%)$. Mean values SD (error bars) were calculated from two separate experiments. (B) Western blot analysis for procaspase- 9 processing in the mitochondrial and cytosolic fractions. Five portions of each mitochondrial fraction were loaded in parallel with one portion of the corresponding cytosol fraction. The contents of COX IV and HSP90 were also analyzed to verify the purity of these fractions. 
declined at $5 \mathrm{~h}$. In contrast, cytosolic LEHDase activation became evident at $5 \mathrm{~h}$, with a further increase ( 2.5 -fold) at $7 \mathrm{~h}$. These data indicated that under such conditions the initial caspase- 9 activation was associated with mitochondria, and that the cytosolic caspase induction and amplification occurred later on, in both $+/+$ and fog/fog cells.

\section{Discussion}

Using the splenocytes and BMMC from normal and fog/fog mice, we detected two distinguished modes of mitochondrially controlled apoptosis. STS evidently induced the Apaf-1-dependent pathway associated with $\Delta \psi m$ disruption and cytochrome $c$ release, supporting the apoptosome model. On the other hand, both $+/+$ and fog/fog cells were able to induce procaspase- 9 auto-processing and the downstream reactions in response to varied stimuli related to physiological regulators: $\mathrm{H}_{2} \mathrm{O}_{2}$ representing cellular ROS; Sin-1 that releases peroxynitrite $\left(\mathrm{ONOO}^{-}\right)$involved in cardiovascular and other pathologies via its oxidative and nitrosative actions [34, 35]; and UV-C irradiation causing DNA damage and p53 activation [36]. With Apafl-null MEF, we also detected induction of the Apaf-1-independent pathway by oxidative stress.

Unlike the general thought of STS, a recent comprehensive study in chemical biology unequivocally characterized it as a nonspecific kinase inhibitor [37]. The marine mollusk alkaloid lamellarin D acts as a strong inducer of apoptosis by causing $\Delta \psi \mathrm{m}$ disruption and permeability transition pore opening [38]. STS might also directly destroy $\Delta \psi \mathrm{m}$ to cause cytochrome $c$ release and mitochondrial swelling. The apoptosome model may be more relevant to apoptosis induced by acute stressors including ischemia reperfusion [39] and arsenic trioxide [40] than that by physiological stresses caused by homeostatic imbalance. Of note, these acute stimuli lead to a high level production of ROS to destroy $\Delta \psi \mathrm{m}[39,40]$.

Apaf-1-independent caspase-9 activation occurred under the hypo- $\Delta \psi \mathrm{m}$ condition directly indicative of impairment of the ATP-synthesizing function. Indeed, we detected a large decrease in ATP amount upon the hypo-polarization. Despite the inner membrane damage, cellular ATP-consuming reactions may have continued in the $\mathrm{H}_{2} \mathrm{O}_{2}$-stimulated cells. Since the apoptosome formation requires ATP, this ATP depletion might be suppressive of the Apaf-1-dependent pathway. On the other hand, (d)NTPs at the physiological levels block cytochrome $c$ from Apaf-1-binding in vitro [31]. In agreement with the recent result, our experiment also detected a modest decrease in ATP after the $\Delta \psi \mathrm{m}$ disruption by STS. Apoptosis induction may be influenced in multiple mechanisms by ATP.

The Apaf-1-independent cell death induction by the varied stimuli was attenuated by TRX, implying involvement of ROS generated from the respiratory chain. Intriguingly, we detected accumulation of citric acid in BMMC manifesting hypo- $\Delta \psi \mathrm{m}$, suggesting the feedback regulation of the Krebs cycle by the respiratory chain [33]. More specifically, $\left[\mathrm{O}_{2}\right]^{-}$produced from the respiratory chain inactivates aconitase, an iron-sulfur $(\mathrm{Fe}-\mathrm{S})$ protein that catalyzes hydration of citrate at the beginning of the Krebs cycle, and thereby causes citrate accumulation in the matrix [12]. Given the nucleus/cytoplasm volume ratio, $7 / 10$ [41], and the mitochondria/cytosol ratio, 6.2/100, the maximum citrate concentration in the total mitochondrial volume would reach $\sim 125 \mathrm{mM}$. The matrix contains yet a higher concentration of citrate which is emitted to the intermembrane space, where procaspase- 9 molecules exist. Mitochondrial local microenvironments with this citrate accumulation may increase the chance of procaspase- 9 dimer formation (Figure 7), as in vitro studies showed efficient procaspase- 9 homo-dimerization and activation by $1 \mathrm{M}$ ammonium citrate or $0.7-1 \mathrm{M}$ sodium citrate without an alteration of its substrate specificity [21,22].

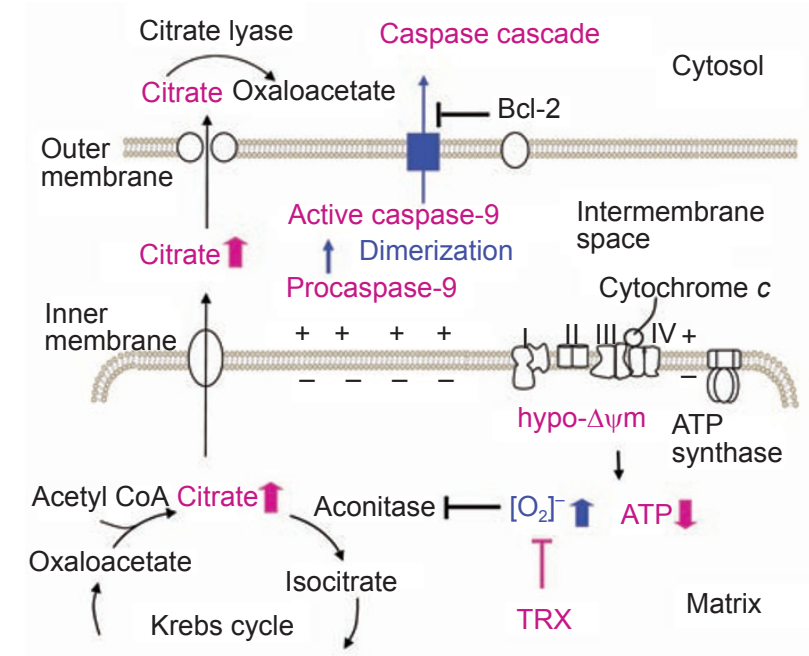

Figure 7 Schematic presentation of the mitochondrial biochemical alterations in the course of Apaf-1-independent caspase-9 activation. The mitochondrial inner membrane is illustrated with the electron transfer system (complexes I-IV), ATP synthase and citrate transporter (oval) [33]. A part of the Krebs cycle in the matrix is depicted. The outer membrane with pores permeable to the metabolites is also shown. Biochemical changes revealed by this study are highlighted in magenta. Bold arrows indicate an increase (upward) or decrease (downward) in each physiological parameter. Bar-headed lines indicate inhibition. The hypo- $\Delta \psi \mathrm{m}$ condition and the results with thioredoxin (TRX) predict free radical $\left(\left[\mathrm{O}_{2}\right]^{-}\right)$ production by which aconitase is inactivated [12]. Dimerization of procaspase- 9 by a topical increase in citrate is hypothesized. Cytosolic translocation of caspase-9 is inhibited by Bcl-2 [24, 26], although the mechanism has not been identified (blue box). 
The newly proposed pathway may respond to gradually increasing physiological stresses and apoptosis signals before the matrix eventually swells by disruption of $\Delta \psi \mathrm{m}$. Due to the technical difficulty in detection of hypo- $\Delta \psi \mathrm{m}$ and intra-mitochondrial caspase- 9 activation, this pathway might have been overlooked or considered to be a non-apoptotic mechanism. Furthermore, although several reports unambiguously showed release of active caspases from mitochondria to the cytosol $[23,24,26]$, the mechanism is yet to be determined, as is the cytochrome $c$-releasing mechanism [8]. In addition to the functions of pro-apoptotic Bcl-2 family proteins [8, 9], ROS-mediated permeability transition pore opening of the inner and outer membranes [12, 42] may be underscored. Supporting the proposition that coupling of caspase- 9 with Apaf- 1 is cellular context-dependent [16], this study suggests that the range of $\Delta \psi \mathrm{m}$ damage is an important parameter for Apaf1-dependent and independent apoptosis pathway usage. In conclusion, we detected Apaf-1-dependent apoptosis by STS in $+/+$ cells, and Apaf-1-independent apoptosis by varied physiological stimuli in $+/+$ and $f \circ g / f \circ g$ cells. The Apaf-1-independent apoptosis seems to involve mitochondrial major metabolic reactions including the electron transfer system and Krebs cycle.

\section{Materials and Methods}

\section{Fog mice}

Heterozygous fog/ + pairs of the fog mice (Jackson Lab Strain Name: STOCK Apaflfog/J) were mated to obtain the fog/fog and $+/+$ progeny mice. At 2 weeks after birth, blood samples $(10 \mu \mathrm{l})$ were obtained from the tail vein for small-scale RNA extraction (RNAqueous, Ambion) for RT-PCR with primer pairs, fogl/fog 13 and fogl/fog 14 [27]. Total RNA preparation from cell cultures was carried out with RNAwiz (Ambion).

\section{Cell cultures and stress induction}

Cells from the spleen and bone marrow were incubated in a buffer $\left(0.14 \mathrm{M} \mathrm{NH}_{4} \mathrm{Cl}, 17 \mathrm{mM}\right.$ Tris-HCl, $\mathrm{pH}$ 7.2) to remove erythrocytes. After two washes, splenocytes were incubated with RPMI 1640 supplemented with $1 \%$ sodium pyruvate, $1 \%$ glutamine, $100 \mathrm{U} / \mathrm{ml}$ penicillin, $0.1 \mathrm{mg} / \mathrm{ml}$ streptomycin, $1 \mathrm{mM}$ non-essential amino acids, $10 \mathrm{mM}$ HEPES and $10 \%$ fetal bovine serum (FBS). Cells from the bone marrow were cultured in the same medium supplemented with $0.1 \%$ 2-mercaptoethanol (2ME) and $4 \mathrm{ng} / \mathrm{ml}$ of IL-3 as described [43] to obtain c-kit/FceRI double-positive BMMC at $80 \%$ homogeneity as judged by flow cytometry. For apoptosis induction, cells were incubated with $\mathrm{H}_{2} \mathrm{O}_{2}(0.1 \mathrm{mM})$, Sin-1 (Dojin) $(0.1 \mathrm{mM})$ or STS (Sigma) $(10 \mu \mathrm{M})$ in the medium without $2 \mathrm{ME}$ for $5 \mathrm{~h}$. UV-C $\left(20 \mathrm{~J} / \mathrm{m}^{2}\right)$ irradiation [36] and a subsequent $5 \mathrm{~h}$ of incubation were also performed. MEF were cultured as described [13], and examined for $\mathrm{H}_{2} \mathrm{O}_{2}(0.2 \mathrm{mM})$-induced cell death in Dulbecco's modified minimum essential medium (with high glucose) supplemented with $20 \%$ FBS. Endotoxin-free recombinant TRX and cell-permeable caspase-9 inhibitor LEHD-CHO (caspase-9 inhibitor II) were from Calbiochem.

\section{Cell fractionation and purification of mitochondria}

Mitochondria were isolated and treated as described [26]. In brief, washed BMMC $\left(10^{7}\right)$ were disrupted with 40 strokes in a loosely fitted Dounce homogenizer in 3 volumes of isolation buffer: 20 mM Hepes, pH 7.4; 10 mM KCl; 1.5 mM MgCl ; 1 mM EDTA; $1 \mathrm{mM}$ EGTA; $1 \mathrm{mM}$ dithiothreitol (DTT); $250 \mathrm{mM}$ sucrose; and protease inhibitors. After two-cycle clarification at $2500 \times g$ for 5 min, supernatant was centrifuged at $12000 \times g$ for $30 \mathrm{~min}$ to obtain the cytosol and mitochondrial fractions. If required, the cytosol fraction was concentrated by centrifugal ultrafiltration units (Vivaspin 2, MWCO 5000, Vivascience).

\section{Western blotting}

For sample preparation, spleen cells $\left(1 \times 10^{7}\right)$ and BMMC $\left(1 \times 10^{6}\right)$ were washed in an ice-cold buffer $(0.15 \mathrm{M} \mathrm{NaCl}, 10 \mathrm{mM}$ Tris- $\mathrm{HCl}$, pH 7.4, 2 mM EDTA, 2 mM EGTA), lysed in $200 \mu$ of SDS-PAGE sample buffer and boiled immediately [26]. Protein quantification was with the BCA protein assay reagent (Pierce). Total cell lysate (100 $\mu \mathrm{g}$ of proteins) was loaded in a slot. The mitochondrial and cytosol fractions were loaded at a ratio of $5: 1$, by which approximately $20 \mu \mathrm{g}$ of proteins were separated in one lane. Separating gel (1.5 mm thick) was prepared with $9 \%$ or $11 \%$ acrylamide. Biotinylated SDS-PAGE standards (broad range, Bio-Rad) were used for size determination. A mouse-specific (\#9504) anti-caspase-9 antibody and an anti-PARP antibody (\#9542) were obtained from Cell Signaling Technology. Antibodies against anti-COX IV (ab16056, Abcam), HSP90 (ab1429, Abcam) and $\beta$-tubulin (Sigma-Aldrich) were used for detection of the loading control proteins. The blotting membrane was exposed to an instant film (FP-3000B, Fuji) with an ECL Mini Camera (Amersham Biosciences).

\section{Cell staining and flow cytometry}

Nuclei were stained with Hoechst 33342 (ICN Biomedicals) to obtain apoptotic cell ratios by counting 500 cells in one experiment [26]. For flow cytometry, cells were stained with $\mathrm{DiOC}_{6}(3)$ (Aldrich) and biotinylated annexin V/streptavidin-allophycocyanin (BD Biosciences), and analyzed by FACS Calibur (BD Biosciences). Carbonyl cyanide 3-chlorophenylhydrazone (Wako), a protonophore abbreviated CCCP, was used as $\Delta \psi \mathrm{m}$ disruptor.

\section{Caspase enzyme assay}

Ac-LEHD-pNA (Calbiochem), a substrate designed for caspase9 , is in fact cleaved not only by caspase- 9 but also by caspase- 3 [29], and the enzyme activity determined by the colorimetric assay is referred to as 'LEHDase'. Mitochondrial and cytosolic fractions in the assay buffer containing Tris- $\mathrm{HCl}(50 \mathrm{mM}, \mathrm{pH} 7.6)$, DTT (10 $\mathrm{mM})$, phenylmethylsulfonyl fluoride $(0.5 \mathrm{mM})$, leupeptin $(1 \mu \mathrm{g} / \mathrm{ml})$, aprotinin $(1 \mu \mathrm{g} / \mathrm{ml})$, and pepstatin $\mathrm{A}(1 \mu \mathrm{g} / \mathrm{ml})$ were incubated with the substrate $(0.2 \mathrm{mM})$ for $10 \mathrm{~min}$ at $37{ }^{\circ} \mathrm{C}$. Isolated mitochondria were permeabilized with $0.1 \%$ Tween- 20 prior to the enzyme reaction. Absorbance at $405 \mathrm{~nm}$ was measured.

\section{Quantification of ATP and citrate}

We semi-quantified cellular ATP amounts by a luciferase enzyme assay system using the CellTiter-Glo Luminescent Assay kit (Promega). Citrate concentration was determined with K-CITR (Megazyme, Wicklow, Ireland), an assay system with citrate lyase and NADH. Aliquots of deproteinated cellular extracts ( $50 \mu \mathrm{l}$ from $10^{8}$ cells) were subjected to the enzyme reaction, and concentrations $(\mathrm{mM})$ calculated from the decrease in absorbance at $340 \mathrm{~nm}$. 


\section{Acknowledgments}

This study was supported in part by Grants-in-Aid for Scientific Research (B) (to TI) and (C) (to SK) from MEXT, Japan. We thank N Shirato, Photography Department, Tokyo Medical and Dental University, for image file editing.

\section{References}

1 Li P, Nijhawan D, Budihardjo I, et al. Cytochrome c and dATPdependent formation of Apaf-1/caspase-9 complex initiates an apoptotic protease cascade. Cell 1997; 91:479-489.

$2 \mathrm{Hu}$ Y, Benedict MA, Ding L, Nunez G. Role of cytochrome c and dATP/ATP hydrolysis in Apaf-1-mediated caspase-9 activation and apoptosis. EMBO J 1999; 18:3586-3595.

3 Liu X, Kim CN, Yang J, Jemmerson R, Wang X. Induction of apoptotic program in cell-free extracts: requirement for dATP and cytochrome c. Cell 1996; 86:147-157.

4 Kroemer G, Dallaporta B, Resche-Rigon M. The mitochondrial death/life regulator in apoptosis and necrosis. Annu Rev Physiol 1998; 60:619-642.

5 Zhou P, Chou J, Olea RS, Yuan J, Wagner G. Solution structure of Apaf-1 CARD and its interaction with caspase-9 CARD: a structural basis for specific adaptor/caspase interaction. Proc Natl Acad Sci USA 1999; 96:11265-11270.

6 Shiozaki EN, Chai J, Shi Y. Oligomerization and activation of caspase-9, induced by Apaf-1 CARD. Proc Natl Acad Sci USA 2002; 99:4197-4202.

7 Srinivasula SM, Ahmad M, Fernandes-Alnemri T, Alnemri ES. Autoactivation of procaspase- 9 by Apaf-1-mediated oligomerization. Mol Cell 1998; 1:949-957.

8 Kroemer G, Galluzzi L, Brenner C. Mitochondrial membrane permeabilization in cell death. Physiol Rev 2007; 87:99-163.

9 Scorrano L, Korsmeyer SJ. Mechanisms of cytochrome c release by proapoptotic BCL-2 family members. Biochem Biophys Res Commun 2003; 304:437-444.

10 Robertson JD, Zhivotovsky B, Gogvadze V, Orrenius S. Outer mitochondrial membrane permeabilization: an open-and-shut case? Cell Death Differ 2003; 10:485-487.

11 Scorrano L, Ashiya M, Buttle K, et al. A distinct pathway remodels mitochondrial cristae and mobilizes cytochrome c during apoptosis. Dev Cell 2002; 2:55-67.

12 Skulachev VP. Membrane-linked systems preventing superoxide formation. Biosci Rep 1997; 17:347-366.

13 Yoshida H, Kong Y-Y, Yoshida R, et al. Apaf1 is required for mitochondrial pathways of apoptosis and brain development. Cell 1998; 94:739-750.

14 Honarpour N, Du C, Richardson JA, et al. Adult Apaf-1-deficient mice exhibit male infertility. Dev Biol 2000; 218:248-258.

15 Marsden VS, O'Connor L, O'Reilly LA, et al. Apoptosis initiated by Bcl-2-regulated caspase activation independently of the cytochrome c/Apaf-1/caspase-9 apoptosome. Nature 2002; 419:634-637.

16 Ho AT, Li QH, Hakem R, Mak TW, Zacksenhaus E. Coupling of caspase-9 to Apaf1 in response to loss of $\mathrm{pRb}$ or cytotoxic drugs is cell-type-specific. EMBO J 2004; 23:460-472.

17 Mills K, Daish T, Harvey KF, et al. The Drosophila melanogaster
Apaf-1 homologue ARK is required for most, but not all, programmed cell death. $J$ Cell Biol 2006; 172:809-815.

18 Hao Z, Duncan GS, Chang C-C, et al. Specific ablation of the apoptotic functions of cytochrome c reveals a differential requirement for cytochrome c and Apaf-1 in apoptosis. Cell 2005; 121:579-591.

19 Renatus M, Stennicke HR, Scott FL, Liddington RC, Salvesen GS. Dimer formation drives the activation of the cell death protease caspase 9. Proc Natl Acad Sci USA 2001; 98:14250-14255.

20 Sadhukhan R, Leone JW, Lull J, et al. An efficient method to express and refold a truncated human procaspase-9: a caspase with activity toward Glu-X bonds. Protein Expr Purif 2006; 46:299-308.

21 Boatright KM, Renatus M, Scott FL, et al. A unified model for apical caspase activation. Mol Cell 2003; 11:529-541.

22 Pop C, Timmer J, Sperandio S, Salvesen GS. The apoptosome activates caspase-9 by dimerization. Mol Cell 2006; 22:269275.

23 Samali A, Cai J, Zhivotovsky B, Jones DP, Orrenius S. Presence of a pre-apoptotic complex of pro-caspase-3, Hsp60 and Hsp10 in the mitochondrial fraction of Jurkat cells. EMBO J 1999; 18:2040-2048.

24 Susin SA, Lorenzo HK, Zamzami N, et al. Mitochondrial release of caspase-2 and -9 during the apoptotic process. $J$ Exp Med 1999; 189:381-394.

25 Costantini P, Bruey JM, Castedo M, et al. Pre-processed caspase9 contained in mitochondria participates in apoptosis. Cell Death Differ 2002; 9:82-88.

26 Katoh I, Tomimori Y, Ikawa Y, Kurata S. Dimerization and processing of procaspase-9 by redox stress in mitochondria. $J$ Biol Chem 2004; 279:15515-15523.

27 Honarpour N, Gilbert SL, Lahn BT, Wang X, Herz J. Apaf-1 deficiency and neural tube closure defects are found in fog mice. Proc Natl Acad Sci USA 2001; 98:9683-9687.

28 Mochizuki H, Hayakawa H, Migita M, et al. An AAV-derived Apaf-1 dominant negative inhibitor prevents MPTP toxicity as antiapoptotic gene therapy for Parkinson's disease. Proc Natl Acad Sci USA 2001; 98:10918-10923.

29 McStay GP, Salvesen GS, Green DR. Overlapping cleavage motif selectivity of caspases: implications for analysis of apoptotic pathways. Cell Death Differ 2007; 15:322-331.

30 Zamzami N, Metivier D, Kroemer G. Quantitation of mitochondrial transmembrane potential in cells and in isolated mitochondria. Methods Enzymol 2000; 322:208-213.

31 Chandra D, Bratton SB, Person MD, et al. Intracellular nucleotides act as critical prosurvival factors by binding to cytochrome C and inhibiting apoptosome. Cell 2006; 125:1333-1346.

32 Munday MR. Regulation of mammalian acetyl-CoA carboxylase. Biochem Soc Trans 2002; 30:1059-1064.

33 Nelson DL, Cox MM, eds. Lehninger Principles of Biochemistry. 3rd Edition. New York: Worth Publishers, 2000.

34 Ferdinandy P. Peroxynitrite: just an oxidative//nitrosative stressor or a physiological regulator as well? Br J Pharmacol 2006; 148: $1-3$.

35 Denicola A, Radi R. Peroxynitrite and drug-dependent toxicity. Toxicology 2005; 208:273-288.

36 Katoh I, Aisaki KI, Kurata SI, Ikawa S, Ikawa Y. p51A (TAp63 gamma), a p53 homolog, accumulates in response to DNA damage for cell regulation. Oncogene 2000; 19:3126-3130. 
37 Fabian MA, Biggs WH, 3rd, Treiber DK, et al. A small molecule-kinase interaction map for clinical kinase inhibitors. Nat Biotechnol 2005; 23:329-336.

38 Kluza J, Gallego M-A, Loyens A, et al. Cancer cell mitochondria are direct proapoptotic targets for the marine antitumor drug lamellarin D. Cancer Res 2006; 66:3177-3187.

39 Chen YR, Chen CL, Pfeiffer DR, Zweier JL. Mitochondrial complex II in the post-ischemic heart: oxidative injury and the role of protein S-glutathionylation. J Biol Chem 2007; 282:3264032654.

40 Woo SH, Park IC, Park MJ, et al. Arsenic trioxide induces apoptosis through a reactive oxygen species-dependent pathway and loss of mitochondrial membrane potential in HeLa cells. Int $J$ Oncol 2002; 21:57-63.

41 Boll IT. Documentation of normal and leukemic myelopoietic progenitor cells with high-resolution phase-contrast time-lapse cinematography. Onkologie 2001; 24:395-402.

42 Dussmann H, Kogel D, Rehm M, Prehn JH. Mitochondrial membrane permeabilization and superoxide production during apoptosis. A single-cell analysis. J Biol Chem 2003; 278:1264512649.

43 Asai K, Kitaura J, Kawakami Y, et al. Regulation of mast cell survival by IgE. Immunity 2001; 14:791-800. 